\title{
Vibration analysis of hybrid laminated composite beam
}

Omar A. Mohammed (Assist Lecturer)

College of Engineering / University of Mosul

\begin{abstract}
In this study, the effect of number of carbon layer, its position and orientation angle of the laminate on the natural frequency and mode shape for hybrid fiber (carbon/glass) with epoxy composite laminates are investigated. Numerical analyses are carried out to study vibration behavior of composite laminated beams using ANSYS 13 software. The results show that the natural frequencies increased when the number of carbon layer increases and decreased when the carbon layer position changes from the surface towards mid-plane, also; the natural frequencies change with changing orientation angle.
\end{abstract}

Keywords: natural frequency, composite beam, vibration analysis, FEM

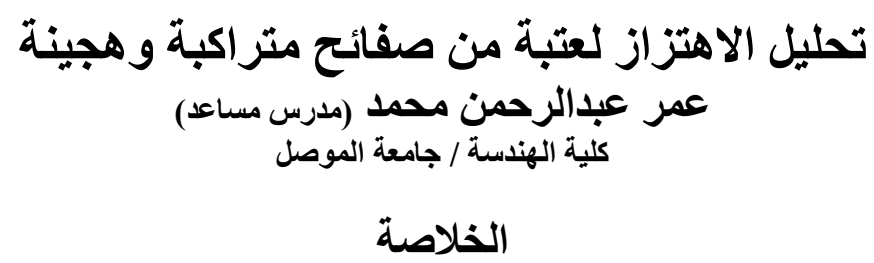

تم دراسة تأثير عدد وموقع طبقات الكاربون وزاوية التوجيه للألياف على مقدار الترددات الطبيعية وأنماط الاهتزازات

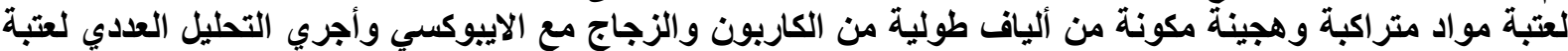

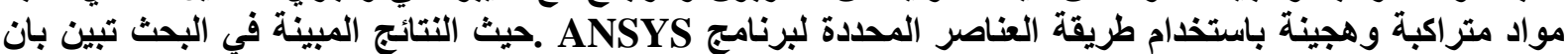

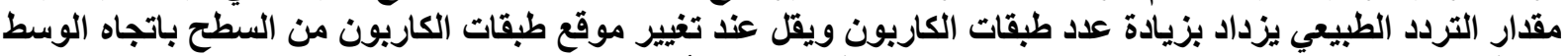

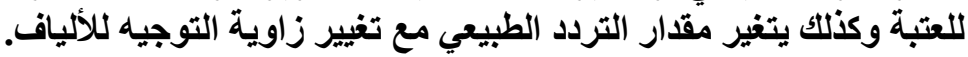
كلمات مفتاحية : التردد الطبيعي، عتبة مادة متراكبة تحليل الاهتزازات ،طريقة العناصر المحددة 


\section{Introduction}

A large variety of fibers is available as reinforcement for composites. The desirable characteristics of most fibers are high strength, high stiffness and relatively low density. Glass fibers are the most commonly used ones in low to medium performance composites because of their high tensile strength and low cost. The combination of different materials has been used for many thousands of years to achieve better performance requirements. The more common composites used are laminated composite plates which are typically made of different layers bonded together. Each layer is generally orthotropic and has a different orientation of the fiber [1].

To avoid the typical problems caused by vibrations, it is important to determine natural frequency. Many researchers studied the vibration analysis in laminated composite. Kapani and Raciti [2] studied the nonlinear vibration of unsymmetrically laminated composite beam. Then Chandrashekhara and Krishanamurthy [3] studied the vibration of symmetric composite beam. Abramovitch [4] studied the effect of shear deformation and rotary inertia on vibration of composite beam. Marur and Kant [5] used a higher order theories and finite element method modeling to investigate the vibration of composite beam. Jafari and Ahmadian investigated free vibration analysis of a cross-ply laminated composite beam . Natural frequencies of beam are computed using finite element technique (FEM) on the idea of Timoshenko beam theory[6]. Yilidirim [7] et al presented a comparison of in plane natural frequencies of symmetric cross ply laminated beams based on the Bernolli-Eueller and Timoshenko beam theories. Erol [8] et al studied the lateral vibration of composite beam. Kaya [9] investigated flexural torsional coupled vibration analysis of axially loaded composite beam. Mirtalaie and Hajabasi [10] gave an analytical approach to study the coupled lateral torsion vibrations of laminated composite beams. Also Hasan and Atlihan [11] studied the effect of delamination length on the natural frequency of symmetric composite beams numerically and analytically.Considering the above, the scope of this research is to present a vibration analysis of hybrid fiber laminated composite material beams having simply supported. The beam consists of carbon/ epoxy and glass/epoxy layers. The effect of number and position of carbon fiber layers, also orientation angles of laminated composite beam on natural frequency and mode shape are investigated numerically using the FEM program, ANSYS.

\section{Mechanical Model and Differential Equation}

The multilayer unidirectional laminated composite beam consisting of twelve layers from carbon/ epoxy and glass/epoxy bonded together. The simply supported beam is with 400 $\mathrm{mm}$. length, $20 \mathrm{~mm}$. width and total thickness $4.8 \mathrm{~mm}$.

The properties of laminates fiber reinforced polymer are obtained experimentally are listed in table $1[12]$.

Table 1 properties of carbon/epoxy and glass/epoxy composite material

\begin{tabular}{|c|c|c|c|c|c|c|c|}
\hline Composite laminate & $\begin{array}{c}\mathrm{E}_{11} \\
\left(\mathrm{GN} / \mathrm{m}^{2}\right)\end{array}$ & $\begin{array}{c}\mathrm{E}_{22} \\
\left(\mathrm{GN} / \mathrm{m}^{2}\right)\end{array}$ & $v_{12}$ & $v_{21}$ & $\begin{array}{c}\mathrm{G}_{12} \\
\left(\mathrm{GN} / \mathrm{m}^{2}\right)\end{array}$ & $\begin{array}{c}\mathrm{G}_{21} \\
\left(\mathrm{GN} / \mathrm{m}^{2}\right)\end{array}$ & $\begin{array}{c}\rho \\
\left(\mathrm{kg} / \mathrm{m}^{3}\right)\end{array}$ \\
\hline Carbon/Epoxy & 170 & 15.0 & 0.41 & 0.04 & 6.2 & 4.2 & 1510 \\
\hline Glass/Epoxy & 77.0 & 39.0 & 0.24 & 0.11 & 4.8 & 3.2 & 1750 \\
\hline
\end{tabular}


Free-body diagram and geometry for a beam element are shown in Fig. 1 for the Timoshenko beam theory, which accounts for both the rotary inertia and the shear deformation of the beam. When the symmetric beam is vibrating transversely, the relation between the moment equilibrium condition, and the inertial moment of the beam element, yields by using the dynamic equilibrium condition for shearing forces in the w-direction [13].

$-V d x+\frac{\partial M}{\partial x} d x-\rho_{m} I_{y y} \frac{\partial^{3} w}{\partial x \partial t^{2}} d x=0$

Where $\mathrm{V}$ is shearing force, $\mathrm{M}$ is internal moment, $\rho_{\mathrm{m}}$ is density and $\mathrm{I}_{\mathrm{yy}}$ is inertia moment. For elementary flexural theory, the bending moment and the curvature can be written as:

$$
M=E_{e f} I_{y y} \frac{d^{2} w}{d x^{2}}
$$

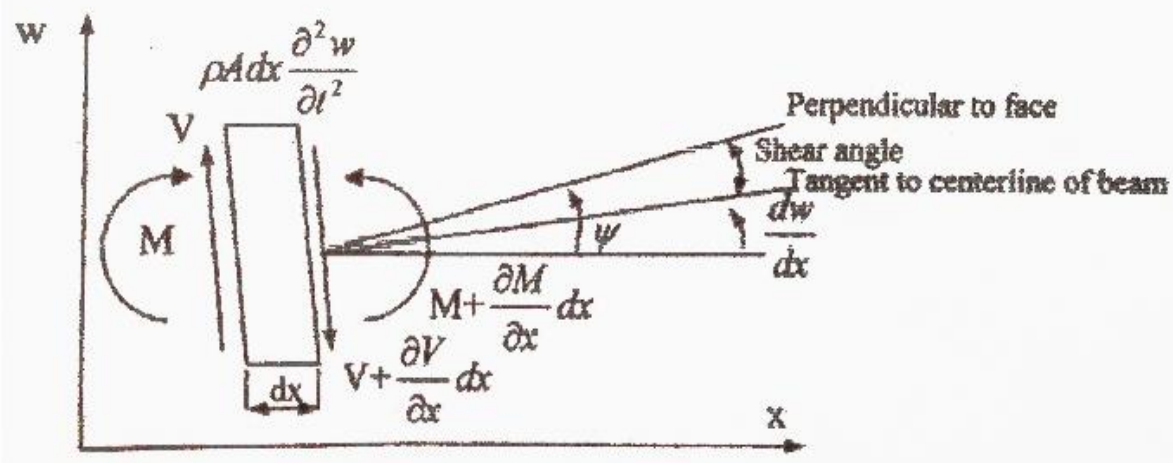

Fig. 1 free body diagram of a deformed beam element

Where, the effective modulus of elasticity is [14].

$$
E_{e f}=\frac{8}{h^{3}} \sum_{j=1}^{\frac{m}{2}}\left(E_{x}\right)_{j}\left(z_{j}^{3}-z_{j-1}^{3}\right)
$$

Where $E_{x}$ is elasticity modulus of $j^{\text {th }}$ layer, $m$ is the number of layer of the beam, $z_{j}$ is the distance between the outer face of $\mathrm{j}^{\text {th }}$ layer and the neutral plane, $h$ is high of the beam, as shown in Fig. 2

The differential equation for the transverse vibration of the prismatic beams can be written as

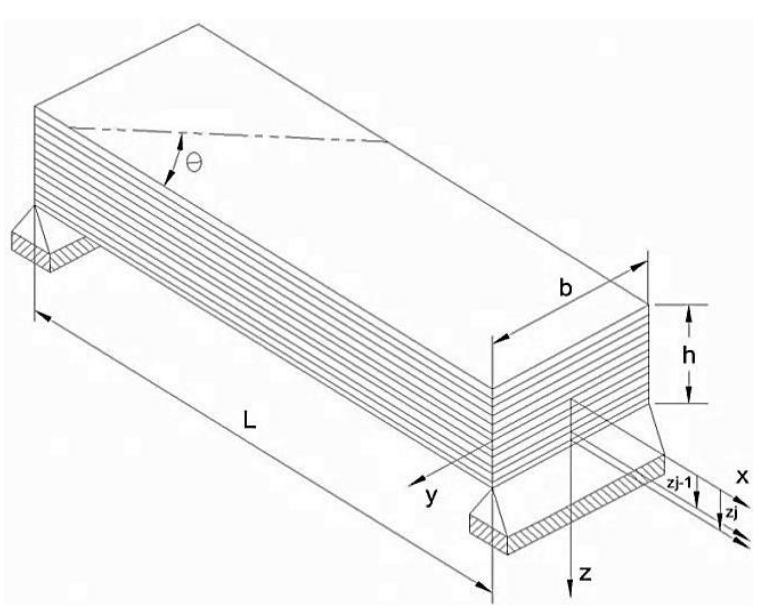

Fig. 2 simply supported laminated composite beam 


$$
E_{e f} I_{y y} \frac{\partial^{4} w(x, t)}{\partial x^{4}}=\rho_{m} I_{y y} \frac{\partial^{4} w}{\partial x^{2} \partial t^{2}}-\frac{\rho_{m} A \partial^{2} w(x, t)}{\partial t^{2}}
$$

The slope of the deflection curve depends not only on the rotation of cross -section of the beam but also on the shearing deformations. If $\psi$ denote the slope of the deflection curve when shearing force is neglected and $\beta$ the angle of shear at the neutral axis in the same cross-section, the total slope can be found as

$\frac{d w}{d x}=\psi+\beta$

The expressions for the bending moment and the shearing force are

$$
\begin{aligned}
& M=E_{e f} I_{y y} \frac{d \psi}{d x} \\
& V=-k \beta A G=-k\left(\frac{d w}{d x}-\psi\right) A G
\end{aligned}
$$

In which $\mathrm{k}$ is the form factor of the cross-section and its $6 / 5$ for rectangular cross-sectional beam.

Eliminating $\psi$, the differential equation for rotation and the translatory motion of an element can be given by

$$
E_{e f} I_{y y} \frac{\partial^{4} w}{\partial x^{4}}+\rho_{m} A \frac{\partial^{2} w}{\partial t^{2}}-\rho_{m} I_{y y}\left(1+\frac{E_{e f}}{k G}\right) \frac{\partial^{4} w}{\partial x^{2} \partial t^{2}}+\frac{\rho_{m}^{2} I_{y y}}{k G} \frac{\partial^{4} w}{\partial t^{4}}=0
$$

When it is considering a simply-supported beam, the equation and the boundary conditions are satisfied by taking

$$
w_{n}=\left(\sin \frac{n \pi x}{L}\right)\left(A_{n} \cos p_{n} t+B_{n} \sin p_{n} t\right)
$$

Where $A_{n}$ and $B_{n}$ are constants and given by:

$A_{n}=\frac{2}{l} \int_{0}^{1} f_{1}(x) \sin \frac{n \pi x}{l} d x$

$B_{n}=\frac{2}{l p_{n}} \int_{0}^{1} f_{2}(x) \sin \frac{n \pi x}{l} d x$

Where $y=f_{1}(x)$ and $y=f_{2}(x)$ represent the initial transverse displacement of any point on the beam (at time $\mathrm{t}=0$ ) and initial velocity, respectively. Substituting Eq. (9) into Eq. (8), the following equation for calculating the frequencies can be obtained

$a^{2} \frac{n^{4} \pi^{4}}{L^{4}}-p_{n}^{2}-p_{n}^{2} \frac{n^{2} \pi^{2} r_{g}^{2}}{L^{2}}-p_{n}^{2} \frac{n^{2} \pi^{2} r_{g}^{2}}{L^{2}} \frac{E_{e f}}{k G}+\frac{r_{g}^{2} \rho_{m}}{k G} p_{n}^{4}=0$

Where $r_{g}=\sqrt{\frac{I_{y y}}{A}}, a=\sqrt{\frac{E_{e f} I_{y y}}{\rho_{m} A}}$

When the last term, which is smaller quantity from the other terms that are the second order, is neglected in order to simplify the solution and to obtain the effects of rotary inertia and shearing deformations, the angular frequencies can be written as 
$p_{n}=\frac{a \pi^{2}}{\lambda_{n}^{2}}\left[1-\frac{\pi^{2} r_{g}^{2}}{2 \lambda_{n}^{2}}\left(1+\frac{E_{e f}}{k G}\right)\right]$

Where

$$
\lambda_{n}=\frac{L}{n}
$$

The natural frequencies are

$\omega_{n}=\frac{p_{n}}{2 \pi}$

\section{Finite Element Modeling}

Finite element method (FEM) known as a powerful tool for many engineering problems has been used to compute such as elastic -plastic, thermal stress, buckling and vibration analysis of the laminated composite beams.

The shell 281element type was selected for 3-D modeling of solid structures in ANSYS 13[15]. Initially, the beams are modeled in order to get initial estimation of the undamped natural frequencies and mode shape. Element type of shell281 may be used for layered applications of a structural shell model. The element has six degrees of freedom at each node; translations in the nodal $\mathrm{x}, \mathrm{y}$ and $\mathrm{z}$ directions and rotation about the nodal $\mathrm{x}, \mathrm{y}$ and $\mathrm{z}$ axes. The model of the hybrid laminated composite beam with twelve layers is generated as shown in Fig 3. This figure shows number of layers and fiber orientation of each layer. Two types of materials are used to model hybrid fiber composite laminate, the outer layers having carbon fiber while inner layers having glass fiber as shown in Fig 4. After mesh generation process, a composite beam has 320 elements and 1129 nodes.

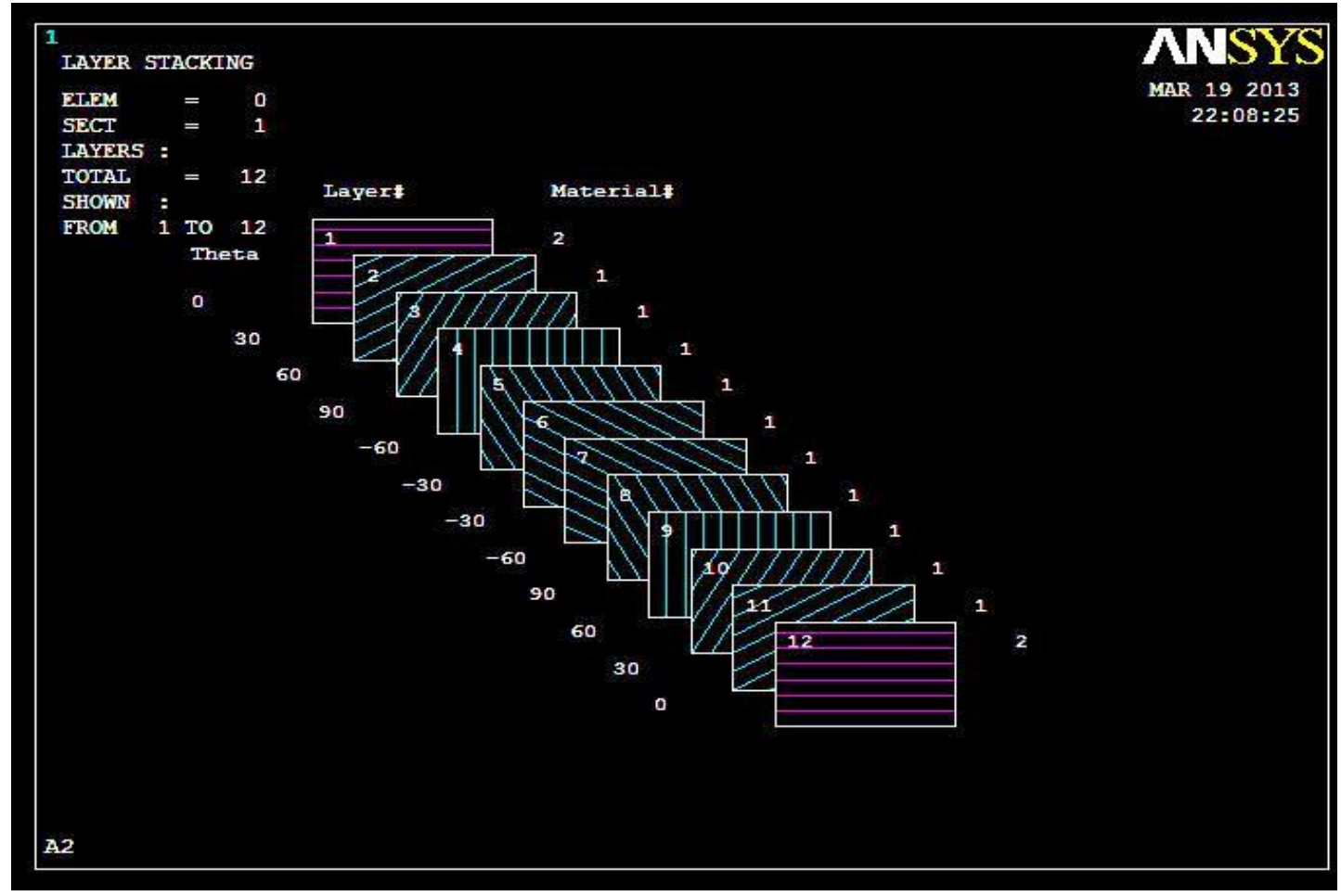

Fig. 3 Section of laminate for case $\mathrm{A}_{2}$ 


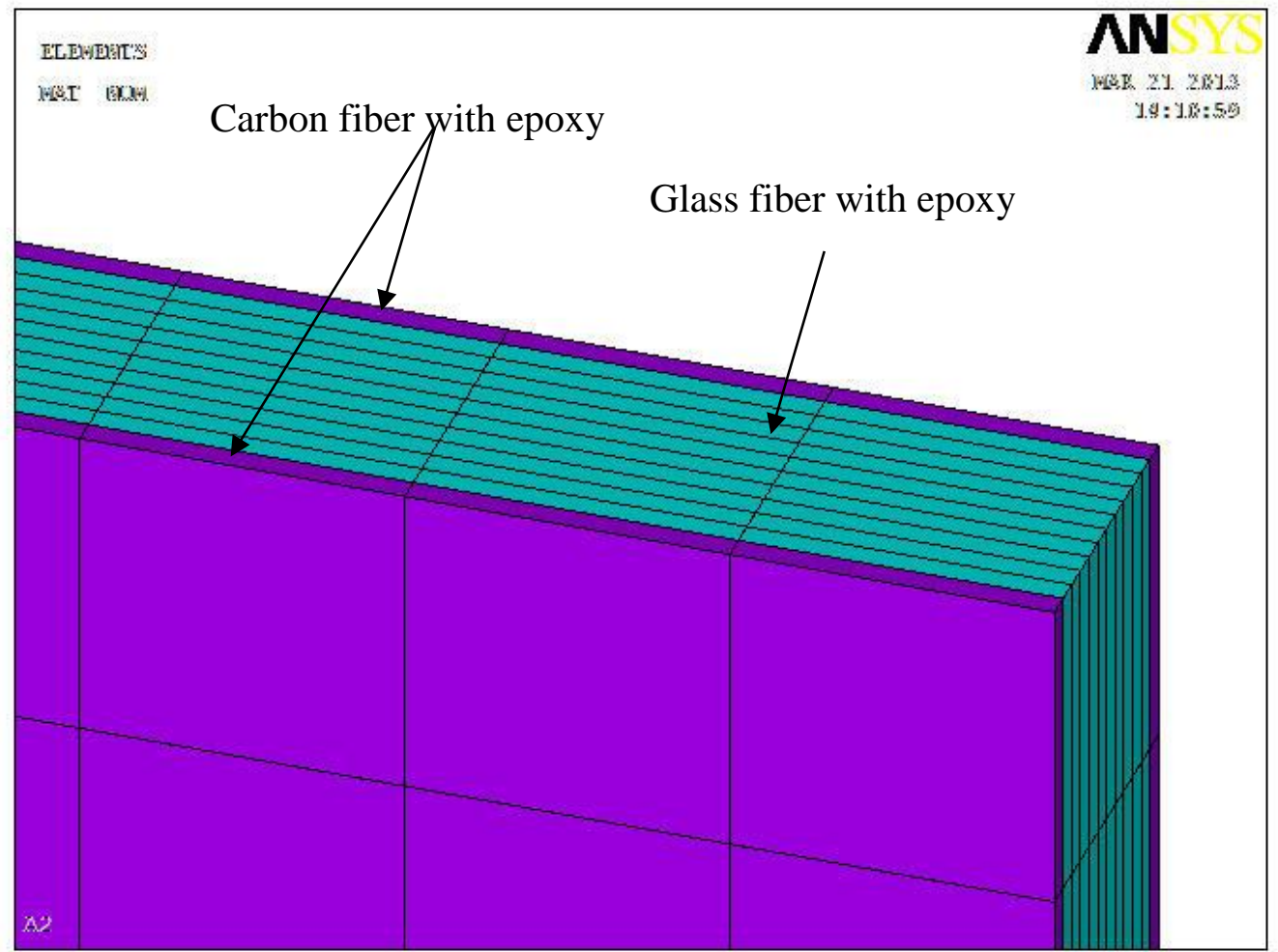

Fig. 4 Materials type of each layer in composite laminate

The case studying is listed in Table 2 .

Table 2 the case studying

\begin{tabular}{|c|c|c|}
\hline case & configuration & description \\
\hline $\mathrm{A}_{1}$ & $\left(\mathrm{G}_{0} / \mathrm{G}_{30} / \mathrm{G}_{60} / \mathrm{G}_{90} / \mathrm{G}_{120} / \mathrm{G}_{150}\right)_{\mathrm{s}}$ & \multirow{4}{*}{$\begin{array}{l}\text { In group A number of carbon/epoxy } \\
\text { layer is increased }\end{array}$} \\
\hline $\mathrm{A}_{2}$ & $\left(\mathrm{C}_{0} / \mathrm{G}_{30} / \mathrm{G}_{60} / \mathrm{G}_{90} / \mathrm{G}_{120} / \mathrm{G}_{150}\right)_{\mathrm{s}}$ & \\
\hline $\mathrm{A}_{3}$ & $\left(\mathrm{C}_{0} / \mathrm{C}_{30} / \mathrm{G}_{60} / \mathrm{G}_{90} / \mathrm{G}_{120} / \mathrm{G}_{150}\right)_{\mathrm{s}}$ & \\
\hline $\mathrm{A}_{4}$ & $\left(\mathrm{C}_{0} / \mathrm{C}_{30} / \mathrm{C}_{60} / \mathrm{G}_{90} / \mathrm{G}_{120} / \mathrm{G}_{150}\right)_{\mathrm{s}}$ & \\
\hline $\mathrm{B}_{1}$ & $\left(\mathrm{G}_{30} / \mathrm{C}_{0} / \mathrm{G}_{60} / \mathrm{G}_{90} / \mathrm{G}_{120} / \mathrm{G}_{150}\right)_{\mathrm{s}}$ & \multirow{3}{*}{$\begin{array}{l}\text { In group B the position of carbon/epoxy } \\
\text { layer is changed with the same } \\
\text { orientation angle of fiber }\end{array}$} \\
\hline $\mathrm{B}_{2}$ & $\left(\mathrm{G}_{30} / \mathrm{G}_{60} / \mathrm{C}_{0} / \mathrm{G}_{90} / \mathrm{G}_{120} / \mathrm{G}_{150}\right)_{\mathrm{s}}$ & \\
\hline $\mathrm{B}_{3}$ & $\left(\mathrm{G}_{30} / \mathrm{G}_{60} / \mathrm{G}_{90} / \mathrm{C}_{0} / \mathrm{G}_{120} / \mathrm{G}_{150}\right)_{\mathrm{s}}$ & \\
\hline $\mathrm{C}_{1}$ & $\left(\mathrm{G}_{0} / \mathrm{C}_{30} / \mathrm{G}_{60} / \mathrm{G}_{90} / \mathrm{G}_{120} / \mathrm{G}_{150}\right)_{\mathrm{s}}$ & \multirow{3}{*}{$\begin{array}{l}\text { In group } \mathrm{C} \text { the position and orientation } \\
\text { angle of carbon/epoxy layer are changed }\end{array}$} \\
\hline $\mathrm{C}_{2}$ & $\left(\mathrm{G}_{0} / \mathrm{G}_{30} / \mathrm{C}_{60} / \mathrm{G}_{90} / \mathrm{G}_{120} / \mathrm{G}_{150}\right)_{\mathrm{s}}$ & \\
\hline $\mathrm{C}_{3}$ & $\left(\mathrm{G}_{0} / \mathrm{G}_{30} / \mathrm{G}_{60} / \mathrm{C}_{90} / \mathrm{G}_{120} / \mathrm{G}_{150}\right)_{\mathrm{s}}$ & \\
\hline $\mathrm{D}_{1}$ & $\left(\mathrm{C}_{0} /\left(\mathrm{G}_{0}\right)_{5}\right)_{\mathrm{s}}$ & \multirow{7}{*}{$\begin{array}{l}\text { In group D the orientation angle of } \\
\text { unidirectional laminate is changed }\end{array}$} \\
\hline $\mathrm{D}_{2}$ & $\left(\mathrm{C}_{15} /\left(\mathrm{G}_{15}\right)_{5}\right)_{\mathrm{s}}$ & \\
\hline $\mathrm{D}_{3}$ & $\left(\mathrm{C}_{30} /\left(\mathrm{G}_{30}\right)_{5}\right)_{\mathrm{s}}$ & \\
\hline $\mathrm{D}_{4}$ & $\left(\mathrm{C}_{45} /\left(\mathrm{G}_{45}\right)_{5}\right)_{\mathrm{s}}$ & \\
\hline$D_{5}$ & $\left(\mathrm{C}_{60} /\left(\mathrm{G}_{60}\right)_{5}\right)_{\mathrm{s}}$ & \\
\hline$D_{6}$ & $\left(\mathrm{C}_{75} /\left(\mathrm{G}_{75}\right)_{5}\right)_{\mathrm{s}}$ & \\
\hline $\mathrm{D}_{7}$ & $\left(\mathrm{C}_{90} /\left(\mathrm{G}_{90}\right)_{5}\right)_{\mathrm{s}}$ & \\
\hline
\end{tabular}




\section{Results and discussion:}

Four cases $\left(A_{1}, A_{2}, A_{3}, A_{4}\right)$ have been studied by increasing the number of carbon/epoxy layers while decreasing the number of glass/epoxy layers of laminated composite beam. Mode shapes and their corresponding frequencies of case $\mathrm{A}_{1}$ are shown in Fig. 5. The effect of increasing the number of carbon/epoxy layers as shown in Fig. 6 led to increase the natural frequencies because of the increasing of the effective elasticity modulus for the beam.

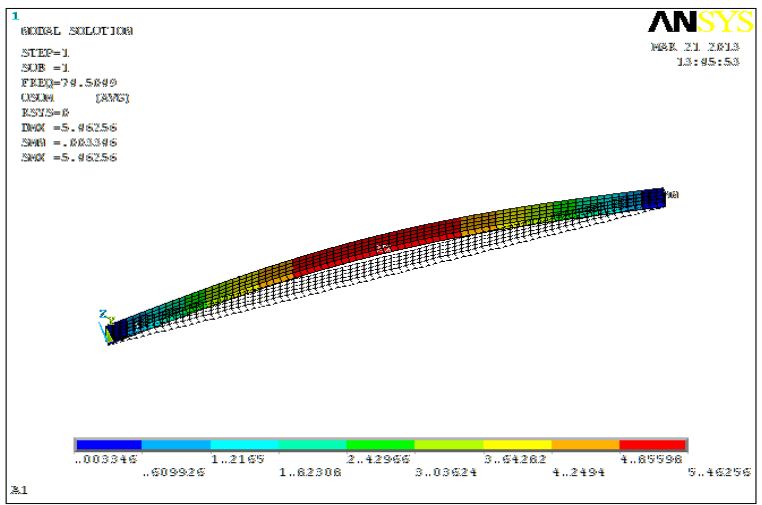

Mode 1

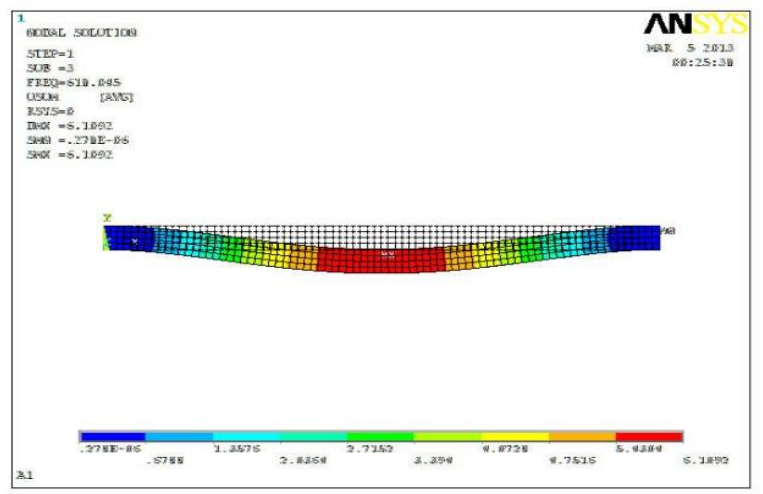

Mode 3

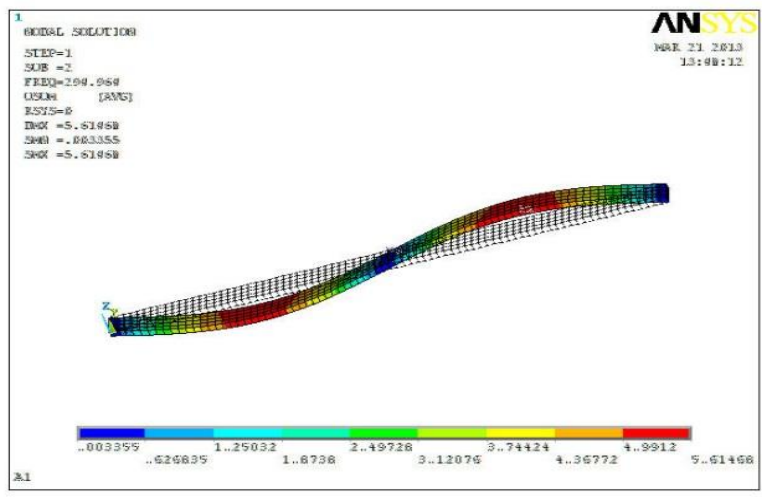

Mode 2

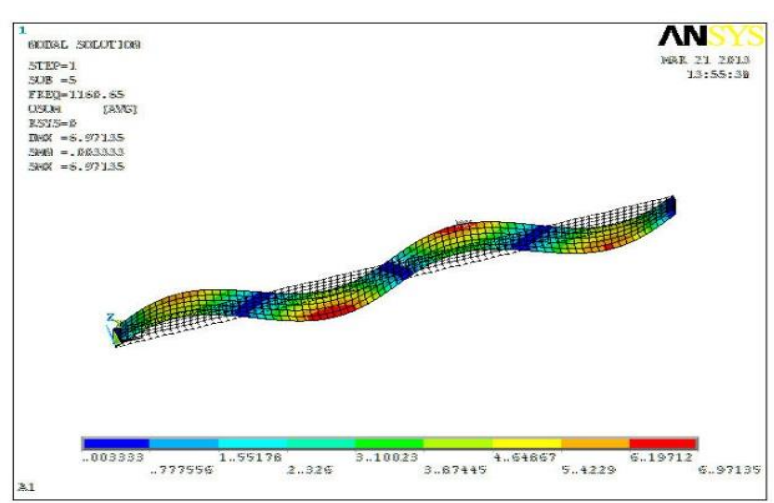

Mode 4

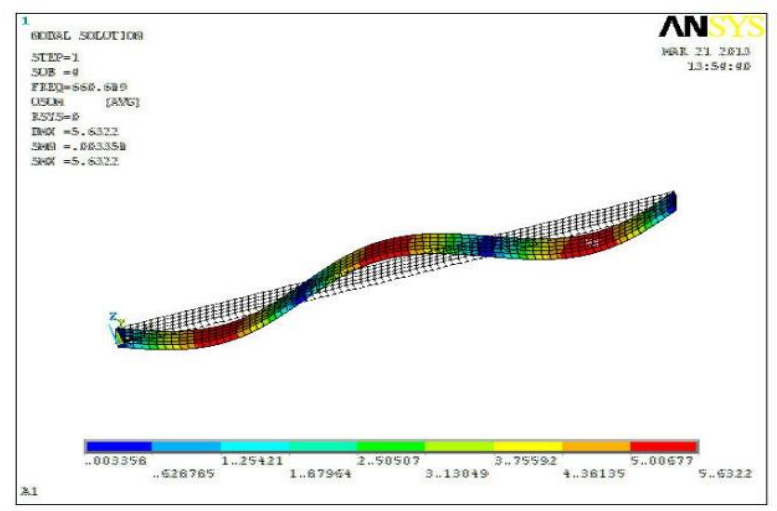

Mode 5

Fig. 5 Mode shapes with natural frequencies for case $A_{1}$ 


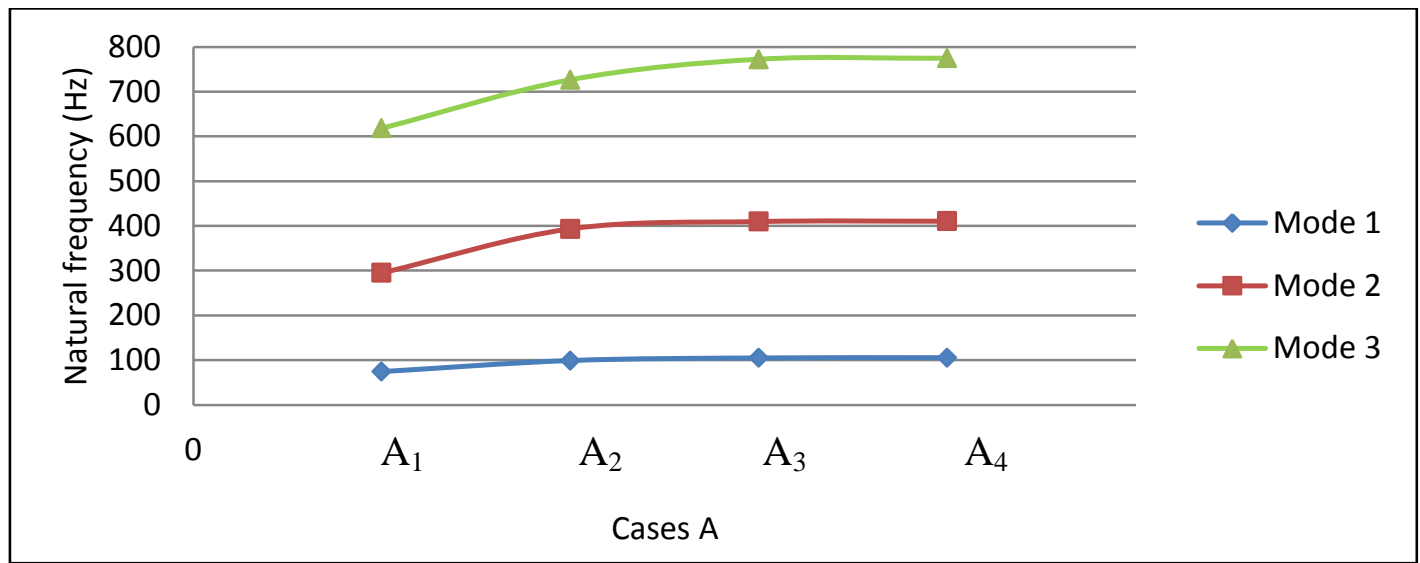

Fig. 6 Effect of increasing carbon layer on natural frequency
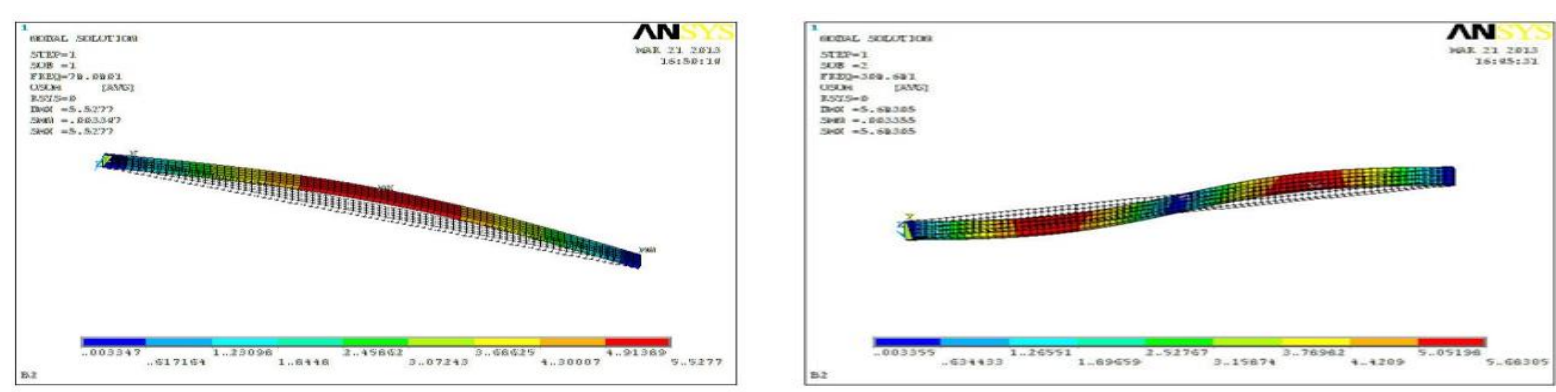

Mode 1

Mode 2
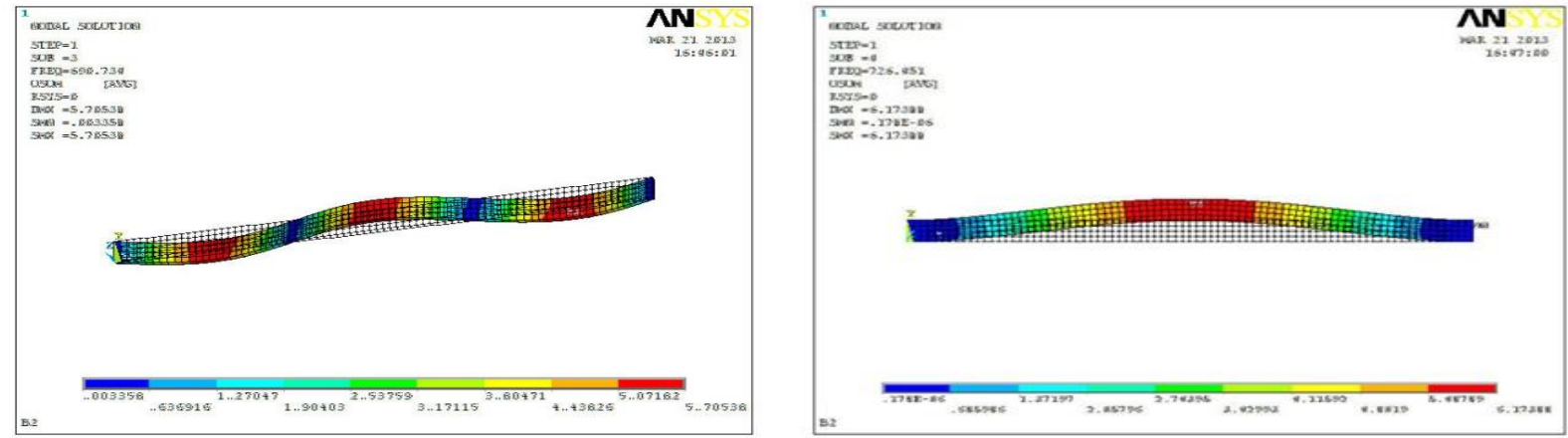

Mode 3

Mode 4

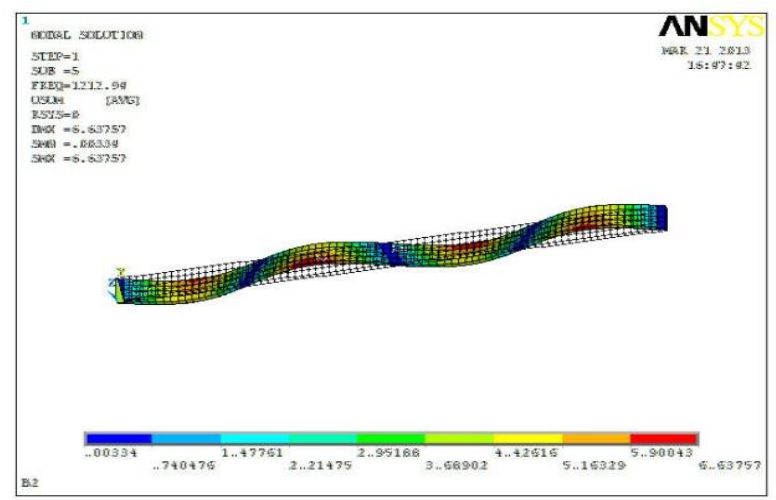

Mode 5

Fig. 7 Mode shapes with natural frequencies for case $\mathrm{B}_{2}$ 
The position of carbon/epoxy layers were changed from the surface towards mid-plane for the cases $\left(\mathrm{A}_{2}, \mathrm{~B}_{1}, \mathrm{~B}_{2}, \mathrm{~B}_{3}\right)$ by keeping the same type and orientation angle of the other layers. Fig.7 represents the mode shapes associated to the natural frequencies of case $\mathrm{B}_{2}$. It can be shown that the natural frequencies decreased, as shown in Fig.8 because of the decreasing of the effective elasticity modulus for the beam.

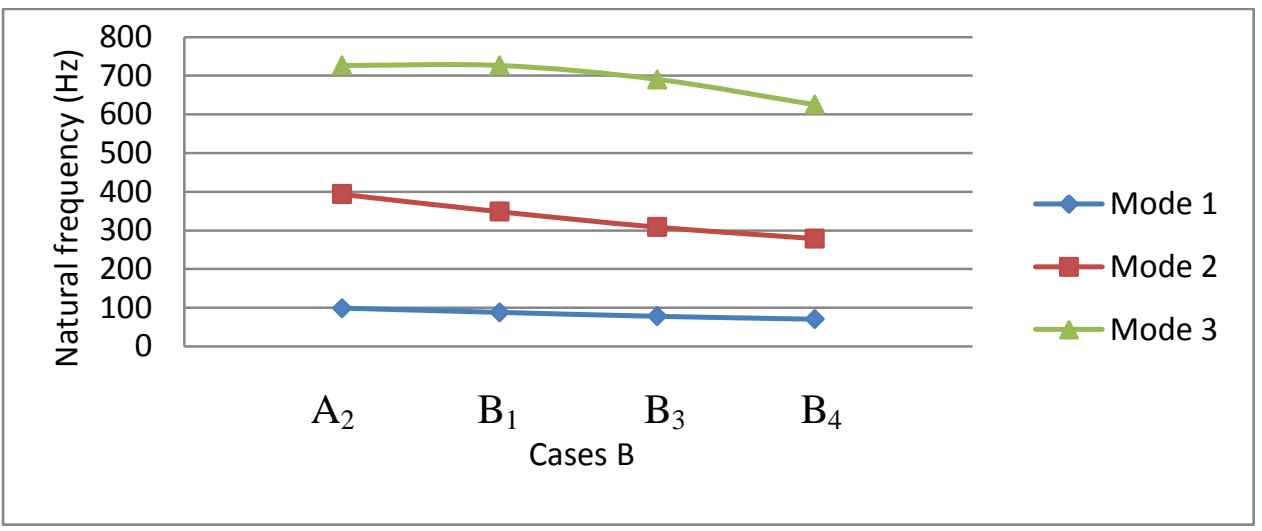

Fig. 8 Effect of changing position carbon layer on natural frequency

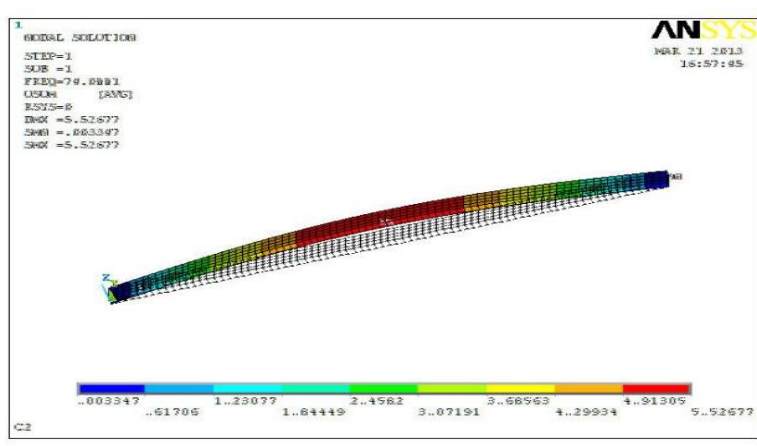

Mode 1

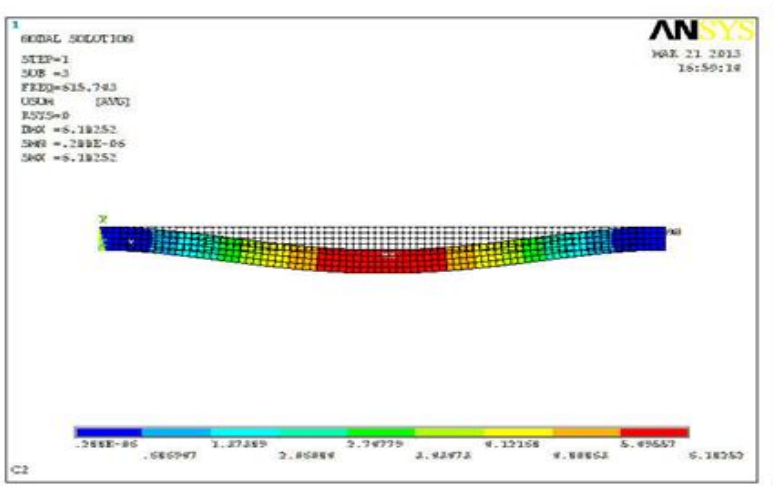

Mode 3

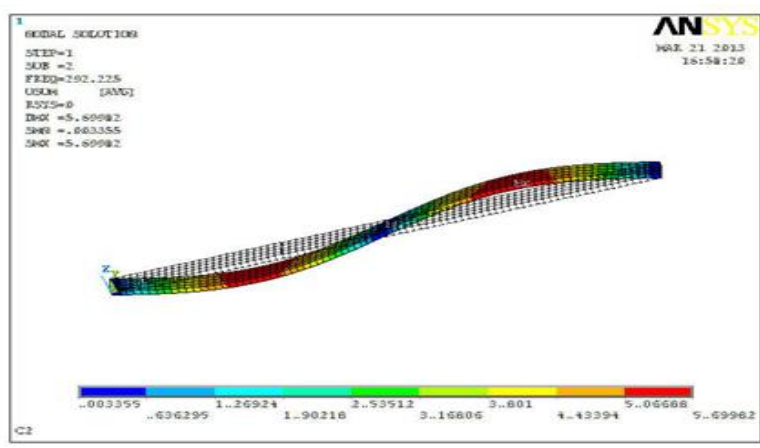

Mode 2

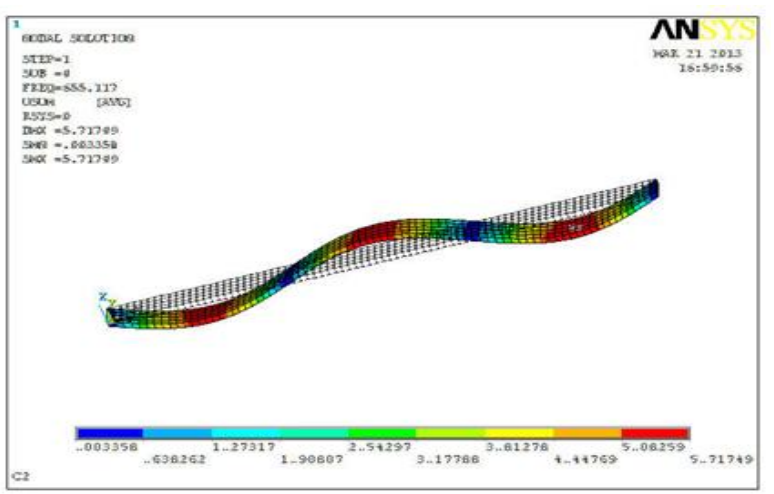

Mode 4 


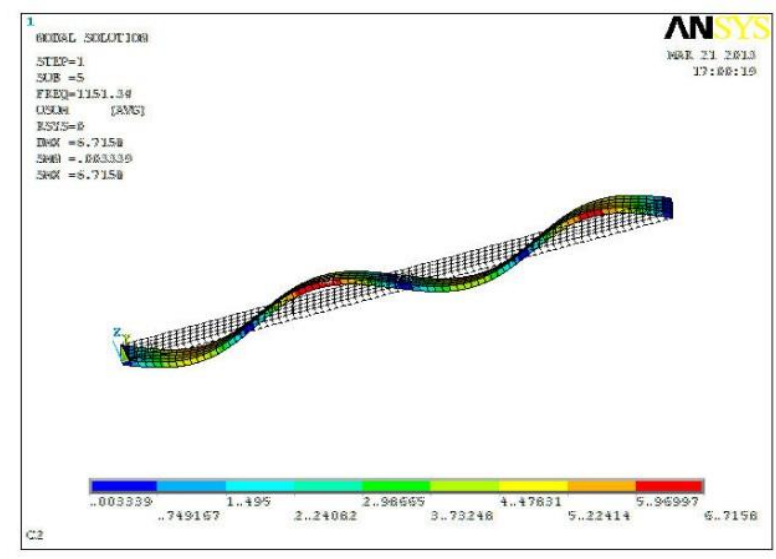

Mode 5

Fig. 9 Mode shapes with natural frequencies for case $\mathrm{C}_{2}$

Four cases $\left(A_{2}, C_{1}, C_{2}, C_{3}\right)$ have been studied by changing the position from surface towards mid-plane and orientation angle of carbon/epoxy layers. Fig. 9 illustrate mode shapes and their corresponding frequencies of case $\mathrm{C}_{2}$. It can be shown that the natural frequencies decreased, as shown in Fig. 10 because of the decreasing of the effective elasticity modulus for the beam.

The cases $\left(D_{1}, D_{2}, D_{3}, D_{4}, D_{5}, D_{6}, D_{7}\right)$ have been investigated in order to make comparison for vibration analysis by changing the orientation angle of fiber for laminate composite beam. Fig.11 represent mode shapes associated to natural frequencies of case $\mathrm{D}_{4}$. The values of natural frequency decrease more and more by increasing fiber orientation angle from $0^{\circ}$ until about $50^{\circ}$ whereas after $\Theta=50^{\circ}$ the value increased, as shown in Fig. 12. The largest natural frequency value is obtained with fiber orientation angle 0 .

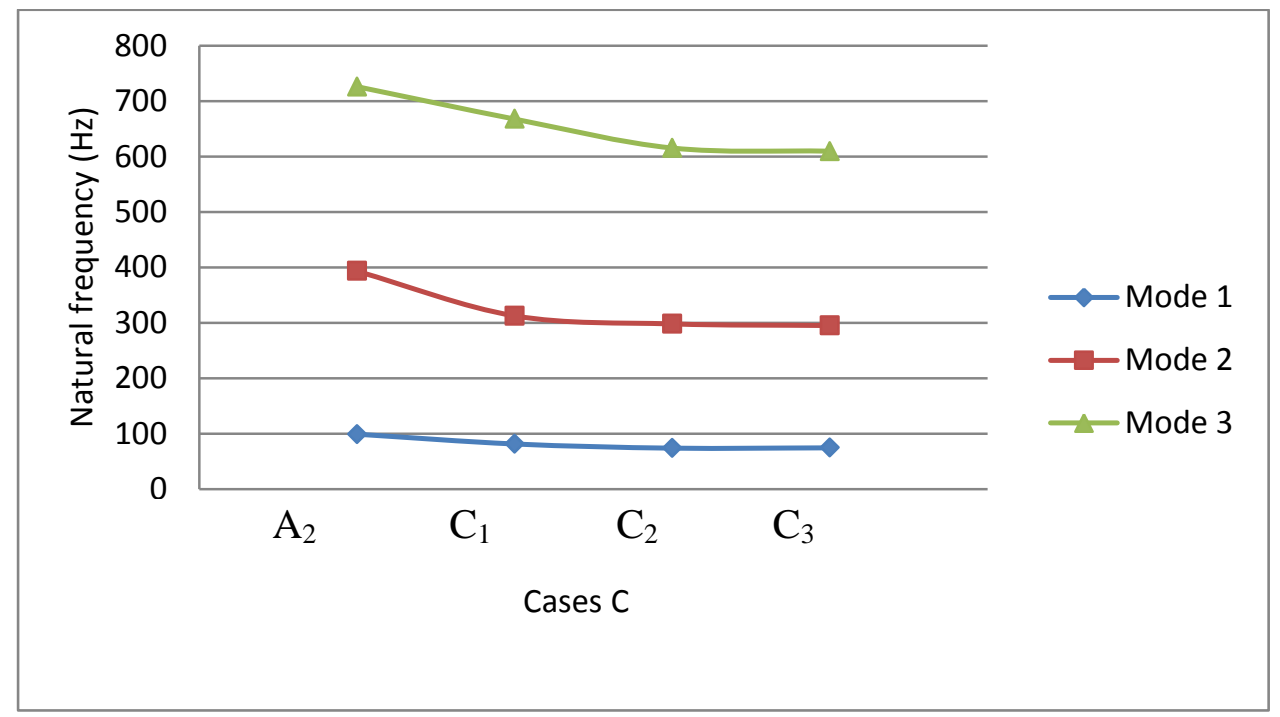

Fig. 10 Effect of changing position and orientation angle of carbon layer on natural frequency 
Mohammed: Vibration analysis of hybrid laminated composite beam

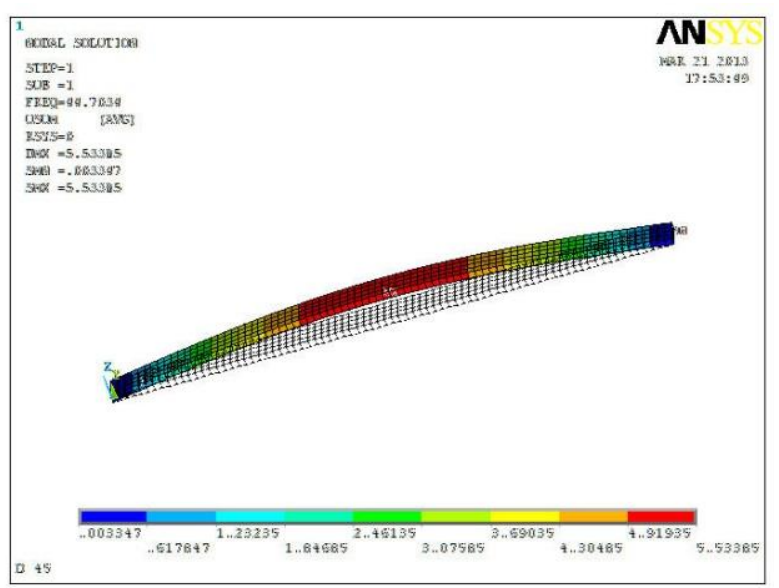

Mode 1

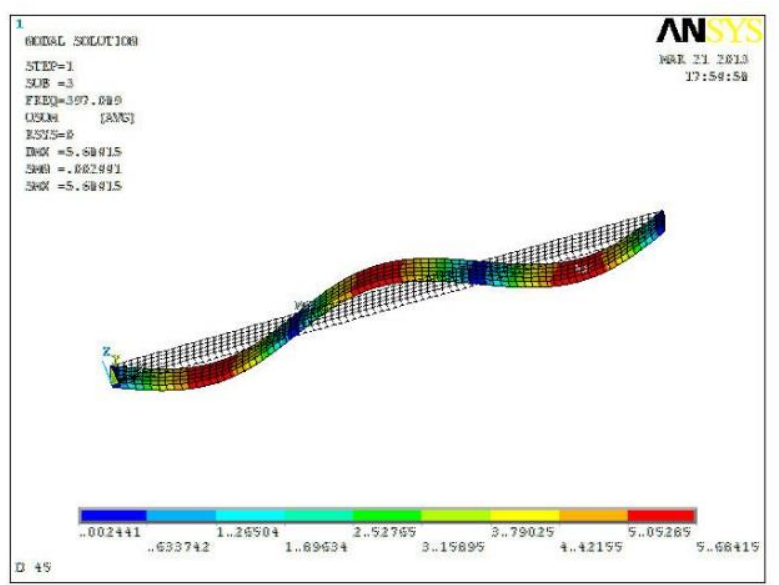

Mode3

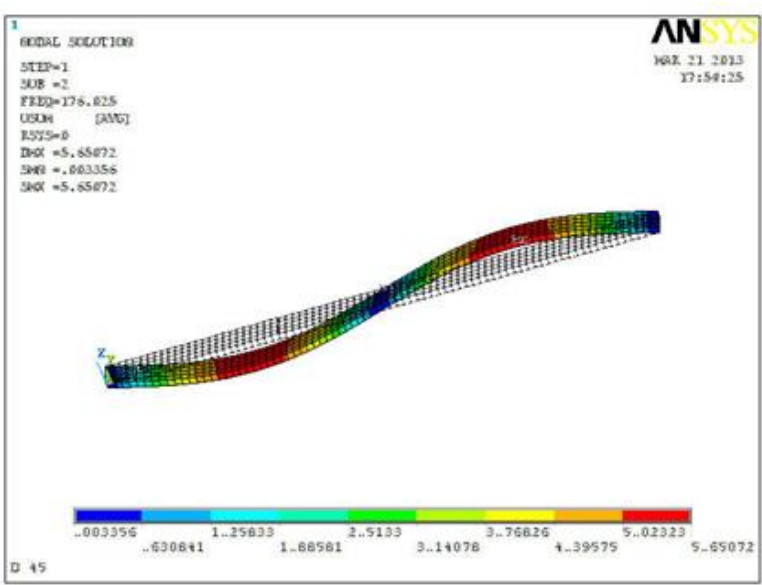

Mode 2

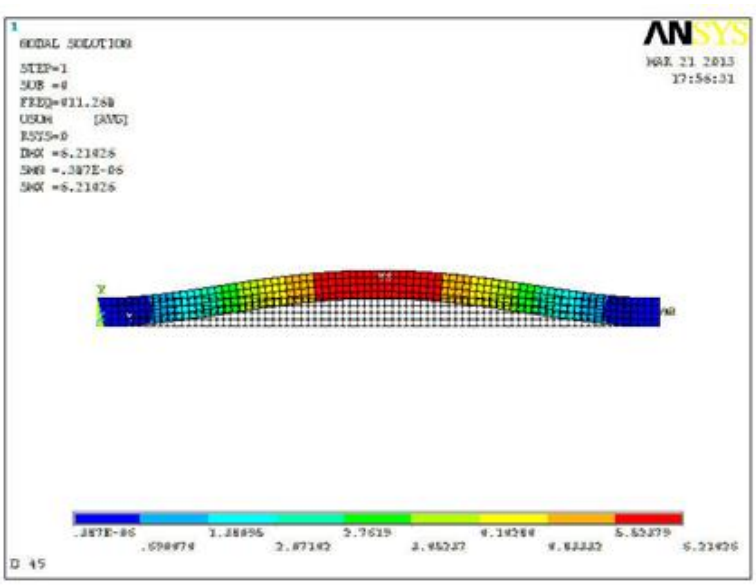

Mode 4

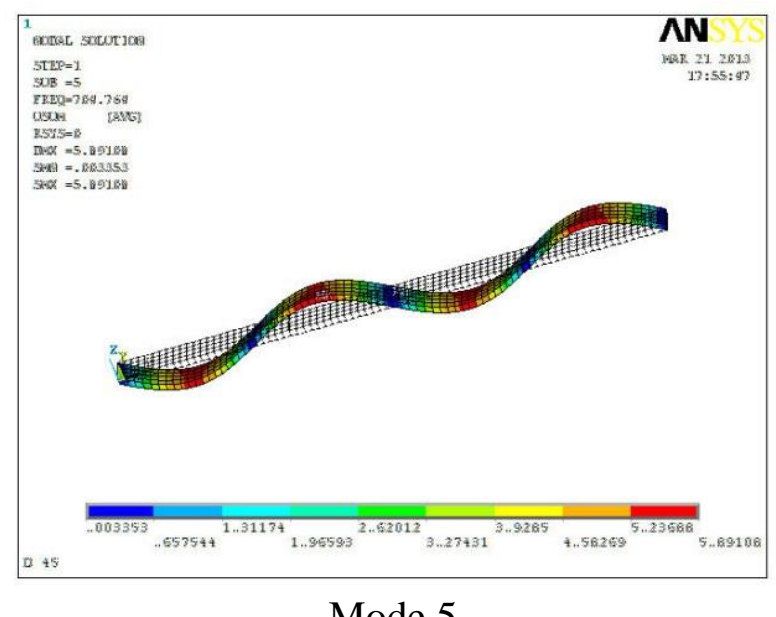

Mode 5

Fig. 11 Mode shapes with natural frequencies for case $\mathrm{D}_{4}$ 


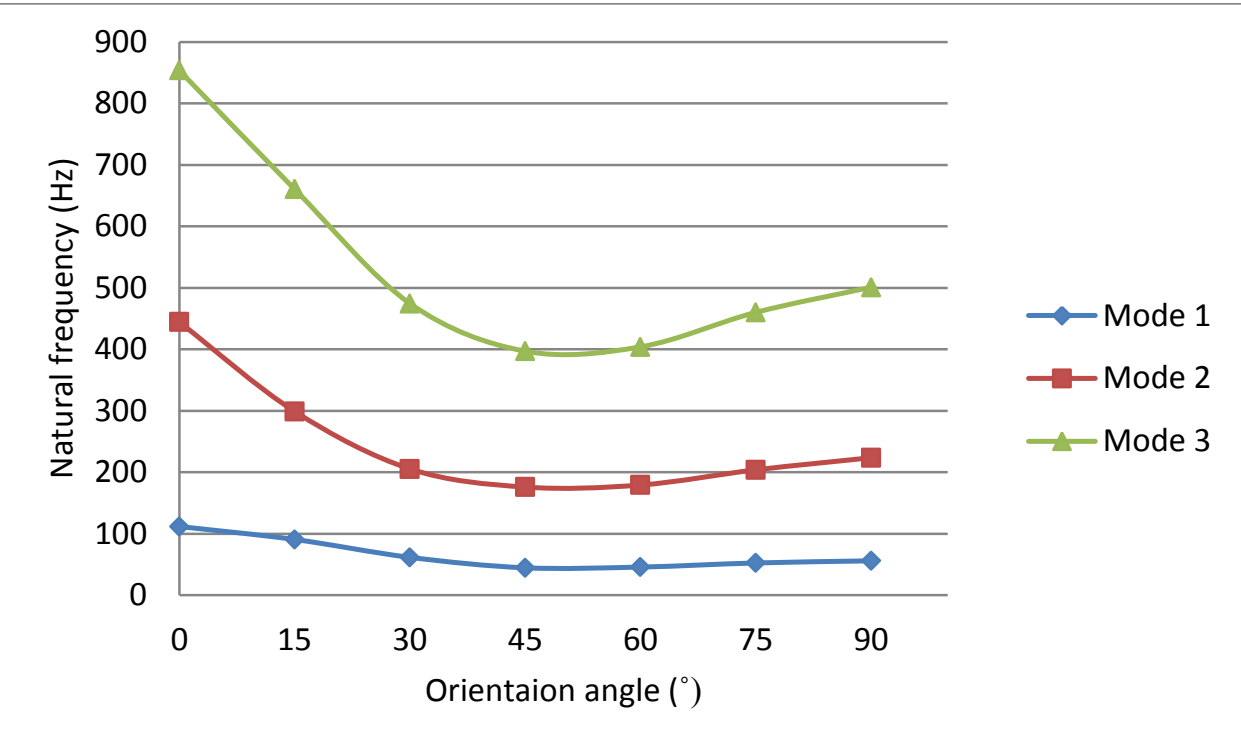

Fig. 12 variation of the natural frequencies with orientation angle for a beam

\section{Conclusions}

1. It is obtained that the natural frequencies increase when the number of carbon/epoxy layers increase.

2. It is also obtained that the natural frequencies decrease when the position of carbon/epoxy layers changing from surface towards mid-plane with and without varying the orientation angle.

3. It is found that the natural frequencies change with the change orientation angle.

4. The largest natural frequency value is obtained with fiber orientation angle of zero.

\section{References}

1. Nayak, P.," Vibration Analysis of Woven Fiber Glass/Epoxy Composite Plate", M.Sc. thesis, National Institute of Technology Rourkela, 2008.

2. Kapani, R.K. \& Raciti S., "Recent advances in analysis of laminated beams and plates", Part II: Vibrations and Wave Propagation, AIAA Journal, 27, 935-946. 1989.

3. Chandrashekhara K., Krishanamurthy and Roy S., "Free vibration of composite beams including rotatory inertia and shear deformation", Composite Structures, vol. 14, pp. 269-279, 1990.

4. Abramovich H., "Shear deformation and rotary inertia effects of vibrating composite beams", Composite Structures“, 20, 165-173, 1992.

5. Marur S.R. and Kant T., "Free vibration analysis of fiber reinforced composite beams using higher order theories and finite element modeling“" Journal of Sound Vibration, 194, 3, 337-351, 1996.

6. Jafari-Talookolaei R. \& Ahmadian M., "Free Vibration Analysis of a Cross-Ply Laminated Composite Beam on Pasternak Foundation", Computers \& Structures, 69, 197-208, 1998.

7. Yildirim V., "Rotary inertia, axial and shear deformation effects on the in-plane natural frequencies of symmetric cross-ply laminated circular arches," J. Sound. Vib., vol. 224, no. 4, pp. 575-589, 1999. 
8. Erol H. \& Gürgöze M. "On laterally vibrating beams carrying tip masses, coupled by several double spring-mass systems"., Journal of Sound and Vibration, 269, 1-2, 431438, 2004.

9. Kaya M.O. and Ozdemir O., "Flexural-torsional-coupled vibration analysis of axially loaded closed-section composite Timoshenko beam by using DTM", J. Sound Vib., vol. 306, pp. 495- 506, 2007.

10. Mirtalai S.H. and Hajabasi M.A. "study of coupled lateral-torsional free vibrations of laminated composite beam", world academy of science, engineering and technology, 78, 2011.

11. Hasan C. and Gokmen, "Vibration analysis of delaminated composite beams using analytical and FEM models", Indian Journal of Engineering and materials sciences, Vol. 18, pp. 7-14, 2011.

12. Mohmeed S.A., "Experimental study and finite element analysis on delaminated buckling of hybrid laminated composites", M.Sc. thesis, Anna University, 2012.

13. Timoshenko S.," Vibration problems in engineering ", New York, USA, 432-435, 1990.

14. Gibson R., "Principles of composite material mechanics", 190-267, 1994.

15. elp of the ANSYS Program V13.

The work was carried out at the college of Engineering. University of Mosul 